\title{
Air pollution and hospital admission in patients with chronic obstructive pulmonary disease in Tehran, Iran
}

\author{
Hasan Amiri' , Ali Bidari', Samad Shams Vahdati2 ${ }^{*}$, Nilofar Ghodrati ${ }^{3}$, Tayeb Ramim4 ${ }^{4}$, Masumeh Emamverdy² \\ 'Emergency Department, Iran University of Medical Sciences, Tehran, Iran \\ ${ }^{2}$ Road Traffic Injury Research Center, Tabriz University of Medical Sciences, Tabriz, Iran \\ ${ }^{3}$ Department of Hematology Oncology, Alborz University of Medical Sciences, Karaj, Iran \\ ${ }^{4}$ Sina Trauma and Surgery Research Center, Tehran University of Medical Sciences, Tehran, Iran
}

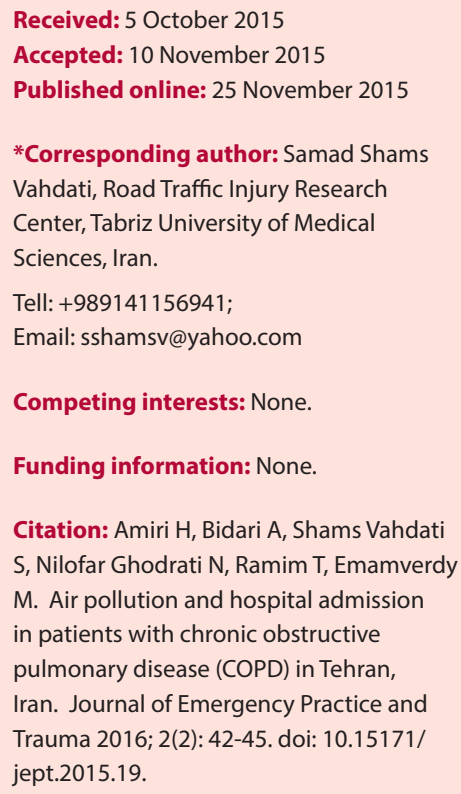

\begin{abstract}
Objective: There are many communities at risk by a series of air pollution episodes. Tehran is one of the most polluted cities in the world. The presence of one or more air pollutants with a certain concentration in a particular period of time can cause several adverse effects on human and animals' well-being that can cause much morbidity. There are several pollutants in the air but some of them can cause severe adverse effects on the lungs and air ways.

Methods: In this retrospective cross-sectional study 1958 patients with exacerbation of chronic obstructive pulmonary disease (COPD) who were admitted in the emergency department (ED) of Rasol Akram hospital between March 2004 and March 2006 entered the study. Data such as number of admissions, air pollution particles $\left(\mathrm{CO}, \mathrm{SO}_{2^{\prime}} \mathrm{O}_{3^{\prime}} \mathrm{NO}_{2^{\prime}} \mathrm{PM}_{10}\right)$ according to available documents were analyzed.

Results: From 1958 patients who enrolled in this study, 887 (53.5\%) were male and $771(46.5 \%)$ were female. According to statistical analysis, we could observe a significant correlation between the concentration of $\mathrm{Co}, \mathrm{PM}_{10}, \mathrm{So}_{2}$ with $\mathrm{ED}$ admission rate of COPD exacerbation ( $P: 0.031,0.008$, and 0.001 respectively). The effect of $\mathrm{PM}_{10^{\prime}}$ $\mathrm{SO}_{2}$ and Co was more significant respectively in logistic regression on ED admission. Conclusion: There was significant correction between concentrations of air pollutants with number of ED admission for COPD exacerbation. Keywords: Air Pollution, $\mathrm{So}_{2}, \mathrm{No}_{2}, \mathrm{Co}, \mathrm{PM}_{10^{\prime}} \mathrm{O} 3, \mathrm{COPD}$
\end{abstract}

\section{Introduction}

Air pollution is one of the risk factors that increases the severity of heart or lung disease and can cause early death among people living in cities with severe air pollution. Epidemiological studies have shown that air pollution worsens ischemic diseases, increases hospitalization and the frequency of ventricular arrhythmias. All these events occur due to the daily changes of air pollution levels and the impact of long-term exposure to air pollution $(1,2)$. The World Health Organization (WHO) highlights that about 800 thousand people living in the affected cities will die each year before the elderly age (3). A correlation was observed between air pollution, heart and lung disease in an incident that occurred in December 1952 in London, UK (London fog episode). Burning large amounts of coal due to the cold weather was the main factor of smog. About 4000 people during 2 weeks died due to heart and lung problems after the high level of air pollution in the town at that time (4). Also, in 1930, in Belgium, one of the industrial factories produced huge smog pollution that caused a crisis of chest pains and premature deaths. Sixty deaths occurred within 3 days in the area which was due to exacerbation of heart disease followed by air pollution $(5,6)$. Pollutants are divided into two categories based on primary and secondary sources. Primitive types are those that are released primarily from polluting sources such as CO, $\mathrm{SO}_{2}, \mathrm{NO}_{2}$ and $\mathrm{PM}_{10}$. Secondary types are those resulting from chemical reactions in the atmosphere gases caused by sunlight and ultraviolet such as ozone $\left(\mathrm{O}_{3}\right)$. Shortterm exposure can be defined as an exposure to air for a few hours. This exposure can occur while walking near a crowded place for several hours in a polluted day (7). Even, short-term exposure to some pollutants can cause an increased incidence of ischemic events.

Peter et al showed that short-term exposure to PM25 (pollutant particles less than 25 microns in diameter) is like an exposure to heavy traffic for about one or two hours thus triggering the process of cardiac ischemia $(8,9)$. Long-term exposure to pollutants in addition to the shortterm exposure can cause exacerbation of heart and lung 
diseases. However, long-term exposure to pollutants can be seen in people that have lived near large cities for a long time (months and perhaps years). One study in Germany showed that the incidence of cardiovascular disease was more prominent in people who lived less than 150 $\mathrm{m}$ from a major street. Cardiopulmonary disease risk in such people is about 1.8 against normal individuals. These people have more calcification in the heart than others $(9,10)$. There is a reverse relation between cardiovascular events and population amount. For example, people living at a distance up to $50 \mathrm{~m}, 51-100 \mathrm{~m}$ and $101-200 \mathrm{~m}$ from a crowded highway have an exposure risk ratio of heart disease at 1.8, 1.34 and 1.36 respectively in comparison to normal people (11). Tehran is one of the most polluted cities in the world and there are many concerns regarding the public health caused by this pollution. Various studies have been done about the relationship between air pollution and cardiovascular and respiratory diseases as well as mortality and hospitalization rates in major cities in the world $(7,12,13)$.

Similar studies are needed to be conducted in Tehran, Iran in other to highlight the long-term and short-term planning essential in health policy, environmental and traffic investigations. The aim of this study was to evaluate patients who referred with chronic obstructive pulmonary disease exacerbation in the emergency department (ED) and its relationship with the severity of air pollution.

\section{Methods}

A retrospective cross-sectional study was conducted in patients who were admitted at the ED in Rasol Akram hospital, Tehran, Iran follow by COPD exacerbation. The records of all hospitalized patients with a diagnosis of COPD exacerbation and marked with J44.9 code according to the International Classification of Disease version 10 (ICD10) code in 2 years (2010-2012) were extracted. Data of all patients were extracted after a thorough review. There was no sex and age restriction. Information of pollutants in every day of the year was provided by Office of Health and Environment of the Ministry of Health and Medical Education (MoHME) of Iran. Air pollutant concentrations were measured by 10 stations located in different parts of Tehran. In this study, pollutant standards index (PSI) was calculated for matched pollutant parameters and facility of data analysis. Collected data were statistically analyzed by SPSS version 16 using descriptive (mean and standard deviation) and analytical ( $t$ test and $\left.\chi^{2}\right)$ tests. $P<0.05$ was considered statistically significant.

\section{Results}

2400 records of ED and 700 cases in hospitalized patients were studied and finally 1658 cases were enrolled in our study. 567 and 1091 cases were related to 2010 and 2011 years respectively (Figure 1). 887 patients $(53.5 \%)$ were male and 771 patients (46.5\%) were female. 69.5\% (1152 cases) of patients were treated and discharged in the ED.
$28.3 \%$ and $2.2 \%$ of patients were admitted in internal department and intensive care unit (ICU) respectively. Fifty patients (3\%) died due to disease complication. 293 (17.7\%) in the first day and about $90 \%$ in the first 5 days after complication were referred to the emergency room. The mean number of patients that referred with COPD exacerbation was less than two cases per day in most days of the year $(62 \%, 226 / 365)$. The patients were highest in the summer months and early fall which continued in two consecutive years of this study. Hospitalization of patients due to COPD exacerbation in unhealthy days was more than healthy days (Table 1). The maximum pollutant concentration for $\mathrm{CO}, \mathrm{SO}_{2}$ and $\mathrm{PM}_{10}$ was in the autumn, while in the case of ozone $\left(\mathrm{O}_{3}\right)$ the maximum contaminant level was in the summer (Figure 2).

\section{Discussion}

According to the Energy Information Administration (EIA) classification of contamination, Tehran is one of the first ten polluted cities in the world as cities such as Mexico City, Cairo, Shanghai, Jakarta and Bangkok (7). According to Iranian Green Association, approximately 2 million vehicles travel and about 7 million liters of petrol is burnt daily in Tehran. Also, about 4-5 thousands of Tehran citizens die annually due to air pollution (7). Air pollution in Tehran has a great role in health, social and economic indexes. Of the total 731 days, 105 days were polluted (14\% of all days), while the number of patients in these days was about 431 people, equivalent to $26 \%$ of patients. The mean age of all subjects was about 71.1 years which was a little different between men and women (71.23 years in males and 70.91 years in females). A mortality rate of $3 \%$ (50 patients) was observed in the present study which is a high percentage. This can be justified by the fact that Rasool Akram hospital is a referral center for most critically ill patients. In a study conducted by Mills et al, 20 men with a history of myocardial infarction exposed to pollution from gasoline and diesel fuel (polluting particles with a diameter of about 300 microns) were investigated. The findings showed that the heart rate significantly increased (14). On the other hand, air pollution can cause an increase in mortality for heart and pulmonary disease. In a study performed in 2003 in the United States, Europe and Israel, the authors concluded that each $10 \mu \mathrm{g} / \mathrm{m}^{3}$ increase in $\mathrm{PM}_{10}$ correlated with $4.2 \%$ and $1.97 \%$ increase in respiratory and cardiovascular disease (12). This increase in mortality occurs a few days after exposure (lag-period). Lag-period is the time in symptomatic patients after exposure to pollutants that varies from 2-4 days to several weeks $(3,5,7,12)$. However, it was not possible to show the relationship between death and previously contaminated days in this study. We could not do this as we did not have access to a lag-period calculation software. As this study was conducted in one hospital in the west of Tehran that has a different pollution pattern compared to central and east parts of the city, we cannot generalize this finding 


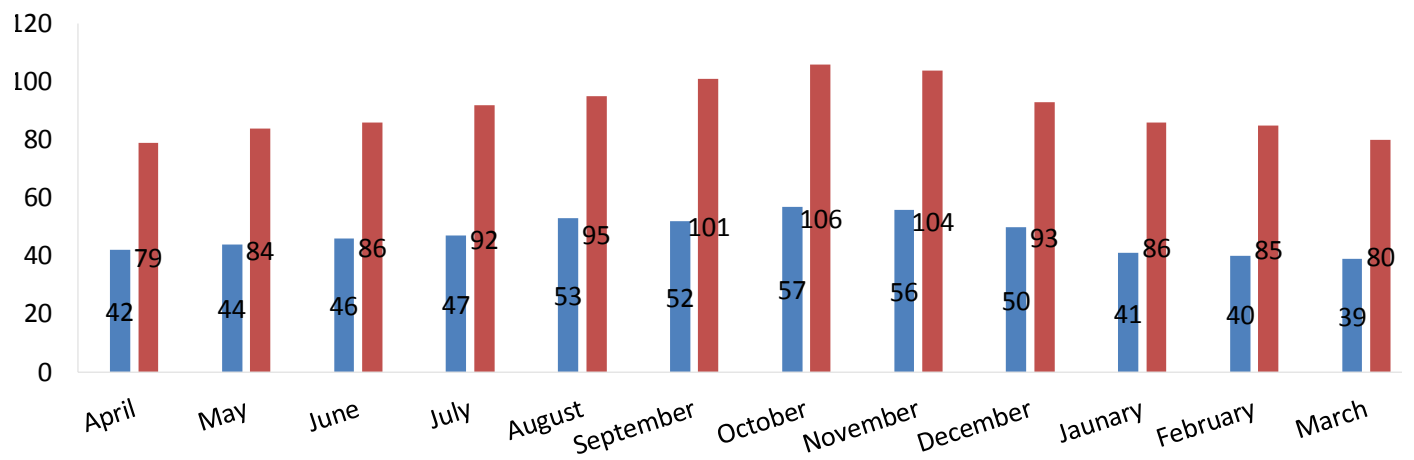

Figure 1. Distribution of referral patients according to months of year.

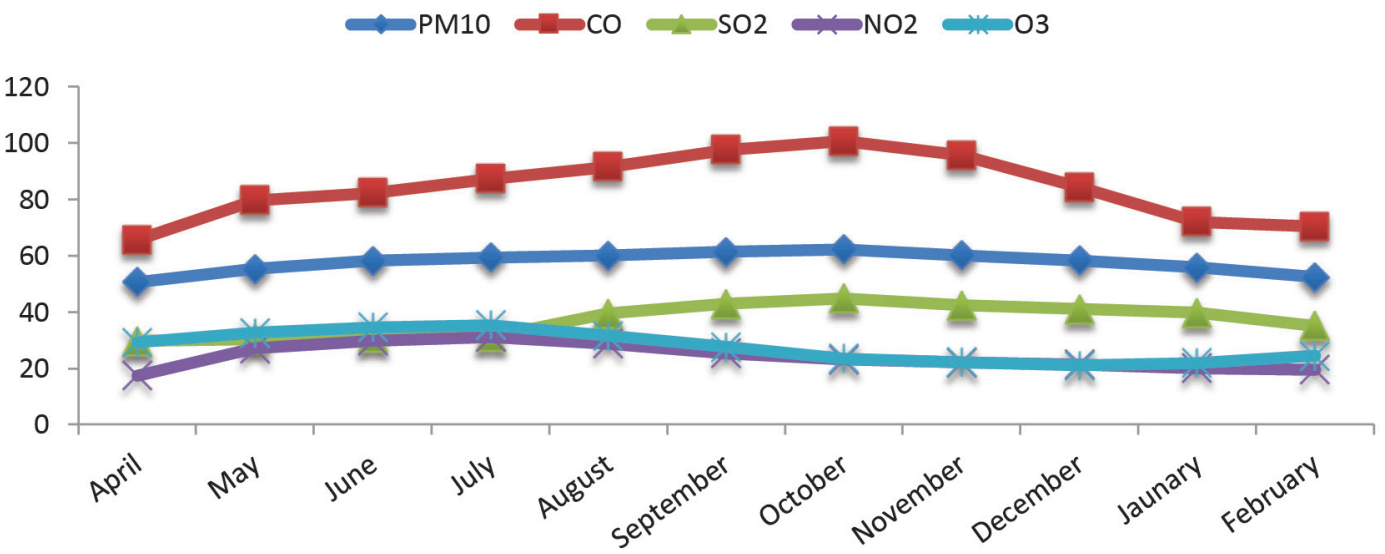

Figure 2. Mean of $\mathrm{PM}_{10}, \mathrm{SO}_{2}, \mathrm{O}_{3}, \mathrm{CO}, \mathrm{NO}_{2}$ according to months of year.

with the general pattern pollution in Tehran. On the other hand, this hospital is a referral center that most patients in the west, southwest and northwest of Tehran are brought here by EMS. In addition, findings showed that when the concentrations of $\mathrm{Co}, \mathrm{PM}_{10}$ or $\mathrm{SO}_{2}$ increased and exceeded the normal limits, the referred patients to the ED with a diagnosis of COPD exacerbation increased significantly as well. But this association was not significant in the case of $\mathrm{NO}_{2}$ and $\mathrm{O}_{3}$. The results also showed the highest correlation between COPD patients and hospital admission due to air pollution with $\mathrm{PM}_{10}$, so each unit concentration of PM10 increased $0.2 \%$ in patients admitted daily. This was also true for $\mathrm{So}_{2}$ and Co with a less strong correlation. According to this study, the effects of pollutant particles in terms of impact on emergency admissions for COPD patients was as follows: $\mathrm{CO}<\mathrm{SO}_{2}<\mathrm{PM}_{10}$. In a study entitled "Air pollution and health: a European epproach (APHEA)" (2) which was conducted simultaneously in 8 European cities, the relationship between daily concentrations of $\mathrm{PM}_{10}$ and emergency admissions of asthma, COPD and respiratory diseases overall were investigated. In this study it was concluded that $\mathrm{PM}_{10}$ concentrations increased the number of emergency room admissions for respiratory diseases, but this increase was different in ev-
Table 1. Mean distribution of patients in healthy days compared with polluted days

\begin{tabular}{lccc}
\hline \multirow{2}{*}{ Pollutants } & \multicolumn{2}{c}{ Patients referral Number } & \multirow{2}{*}{ Analysis $^{\mathbf{a}}$} \\
\cline { 2 - 3 } & Polluted days & Healthy days & \\
\hline $\mathrm{CO}_{2}$ & $2.23 \pm 0.08$ & $1.69 \pm 0.25$ & $P=0.031$ \\
$\mathrm{SO}_{2}$ & $2.90 \pm 2.30$ & $2.10 \pm 2.05$ & $P=0.001$ \\
$\mathrm{PM}_{10}$ & $2.30 \pm 1.99$ & $2.25 \pm 2.05$ & $P=0.008$ \\
$\mathrm{O}_{3}$ & $2.42 \pm 2.10$ & $2.18 \pm 2.09$ & $P=0.503$ \\
$\mathrm{NO}_{2}$ & $2.50 \pm 0.7$ & $2.19 \pm 2.10$ & $P=0.504$ \\
\hline
\end{tabular}

a Data were analyzed by $t$ test. $P<0.05$ was considered as statistically significant.

ery city (2). According to the study of Zanobetti et al, air pollution can affect the mortality of patients not only for a few days, but also up to several months after exposure $(3,5)$. Sunyer performed a study about the daily number of emergency hospital admissions in COPD patients in several cities in Europe, America, and Australia. Sunyer concluded that the admission of COPD correlated with high contaminant concentration days. Also, this association rate in Europe was less than the United States and Australia and the relative risk for COPD admission was higher in comparison with cardiovascular disease (1). The investigation between the rate of heart emergency admis- 
sions and $\mathrm{PM}_{10}$ was studied in a study by Zanobetti et al in several cities of the United States in 2005. The risk of hospitalization was $0.65 \%$ (95\% CI: $0.3-1 \%$ ) with $10 \mu \mathrm{g} /$ $\mathrm{m}^{3}$ increase in $\mathrm{PM}_{10}$ concentration (5). Unfortunately, no comprehensive studies regarding the association between air pollution and various diseases have been done in our country and conducted studies in this area have been sporadic and limited.

\section{Limitations}

The present study has some limitations that they can be resolved in future studies. For example, humidity and air temperature in addition to pollutant concentrations can be examined. Also, participants who referred to one medical ED were included in our study. This limits the generalizability of our findings thus more diverse participants from different parts of the city (different hospitals and EDs) to take part in the study is recommended. In this regard, more comprehensive information can be obtained for health and social policy managers.

\section{Conclusion}

Finally, the results showed that increasing the concentration of air pollutants; especially $\mathrm{PM}_{10}, \mathrm{SO}_{2}$ and $\mathrm{CO}$ has a relation with COPD exacerbation symptoms. This also increases dispatches to the ED.

\section{Ethical issues}

this study was approved by research deputy of medical faculty of Iran University of medical science with number 69 in 22.12 .1384 .

\section{Authors' contributions}

HA; study design. SSV: writing and analyzing. NG, critical check and editing. TR: Data gathering.

\section{References}

1. Sunyer J. Urban air pollution and chronic obstructive pulmonary disease: a review. Eur Respir J 2001; 17(5): 1024-33. doi: 10.1183/09031936.01.17510240.

2. Brook RD, Rajagopalan S, Pope CA 3rd, Brook JR, Bhatnagar A, Diez-Roux AV, et al. Particulate matter air pollution and cardiovascular disease: an update to the scientific statement from the American Heart Association. Circulation 2010; 121: 2331-78. doi: 10.1161/cir.0b013e3181dbece1.

3. Chen L, Verrall K, Tong S. Air particulate pollution due to bushfires and respiratory hospital admissions in Brisbane, Australia. Int J Environ Heal Res 2006; 16(3): 181-91. doi: 10.1080/09603120600641334.

4. UK Ministry of Health. Reports on Public Health and Medical Subjects. London: Ministry of Health; 1954.
5. Zanobetti A, Schwartz J, Samoli E, Gryparis A, Touloumi G, Peacock J, et al. The temporal pattern of respiratory and heart disease mortality in response to air pollution. Environ Health Perspect 2003; 111(9): 1188-93. doi: 10.1289/ehp.5712.

6. Le TG, Ngo L, Mehta S, Do VD, Thach TQ, Vu DX, et al. Effects of short-term exposure to air pollution on hospital admissions of young children for acute lower respiratory infections in Ho Chi Minh City, Vietnam. Res Rep Health Eff Inst 2012; (169): 5-72.

7. Kim SY, Peel JL, Hannigan MP, Dutton SJ, Sheppard L, Clark ML, et al. The temporal lag structure of shortterm associations of fine particulate matter chemical constituents and cardiovascular and respiratory hospitalizations. Environ Health Perspect 2012; 120(8): 1094-9. doi: 10.1289/ehp.1104721.

8. Peters A, Frohlich M, Doring A, Immervoll T, Wichmann HE, Hutchinson WL, et al. Particulate air pollution is associated with an acute phase response in men; results from the MONICA-Augsburg Study. Eur Heart J 2001; 22: 1198-204. doi: 10.1053/ euhj.2000.2483.

9. Romieu I, Gouveia N, Cifuentes LA, de Leon AP, Junger W, Vera J, et al. Multicity study of air pollution and mortality in Latin America. Res Rep Health Eff Inst 2012; (171): 5-86.

10. Kan H, Chen B, Zhao N, London SJ, Song G, Chen $\mathrm{G}$, et al. Part 1. A time-series study of ambient air pollution and daily mortality in Shanghai, China. Res Rep Health Eff Inst 2010; (154): 17-78.

11. Qian Z, He Q, Lin HM, Kong L, Zhou D, Liang S, et al. Part 2. Association of daily mortality with ambient air pollution, and effect modification by extremely high temperature in Wuhan, China. Res Rep Health Eff Inst 2010; (154): 91-217.

12. Merrifield A, Schindeler S, Jalaludin B, Smith W. Health effects of the September 2009 dust storm in Sydney, Australia: did emergency department visits and hospital admissions increase? Environ Health 2013; 12: 32. doi: 10.1186/1476-069X-12-32.

13. Bind MA, Baccarelli A, Zanobetti A, Tarantini L, Suh $\mathrm{H}$, Vokonas $\mathrm{P}$, et al. Air pollution and markers of coagulation, inflammation, and endothelial function: associations and epigene-environment interactions in an elderly cohort. Epidemiology 2012; 23(2): 332-40. doi: 10.1097/ede.0b013e31824523f0.

14. Mills NL, Törnqvist H, Gonzalez MC, Vink E, Robinson SD, Söderberg S, et al. Ischemic and thrombotic effects of dilute diesel-exhaust inhalation in men with coronary heart disease. $\mathrm{N}$ Engl J Med 2007; 357(11): 1075-82. 